Producción visual

Soy el bosque

Valeria, González

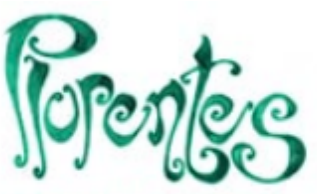

Artes y Letras

\title{
González Valeria
}

valeriagonzalezlp@gmail.com

Bachillerato de Bellas Artes, Universidad Nacional de

La Plata, Argentina

Plurentes. Artes y Letras

Universidad Nacional de La Plata, Argentina

ISSN: 1853-6212

Periodicidad: Anual

núm. 12, e039, 2021

revistaplurentesunlp@gmail.com

URL: http://portal.amelica.org/ameli/

jatsRepo/186/1862378005/index.html

DOI: https://doi.org/10.24215/18536212e039

\section{(c) (1) (3)}

Esta obra está bajo una Licencia Creative Commons AtribuciónNoComercial-CompartirIgual 4.0 Internacional.

\section{OBRA DIGITAL / SOY EL BOSQUE}

Creo en el bosque y soy lo que creo existe en las imágenes de esta serie un diálogo de mundos que coexisten y conviven, como el texto que se forma cuando subrayamos la página de un libro...

una conversación con el misterio

un rastro de la totalidad

\section{Notas DE AUTOR}




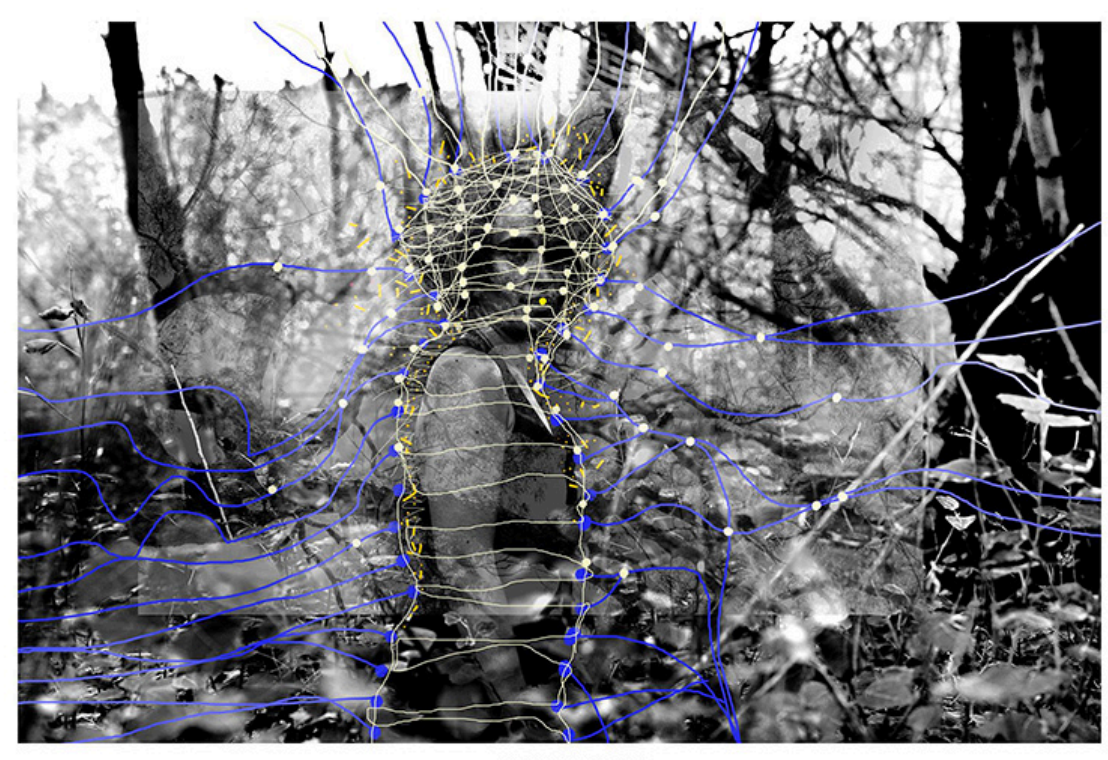

SOY EL BosQuE. VG

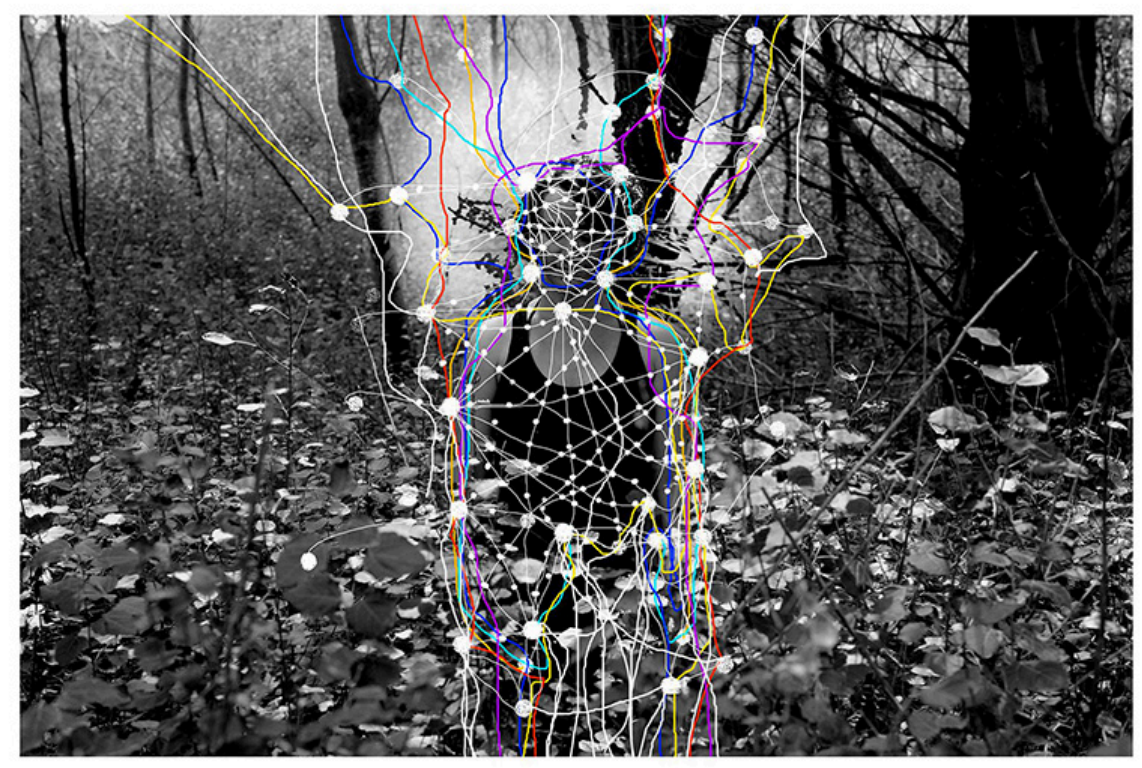

SOY EL BOSQUE. VG* 


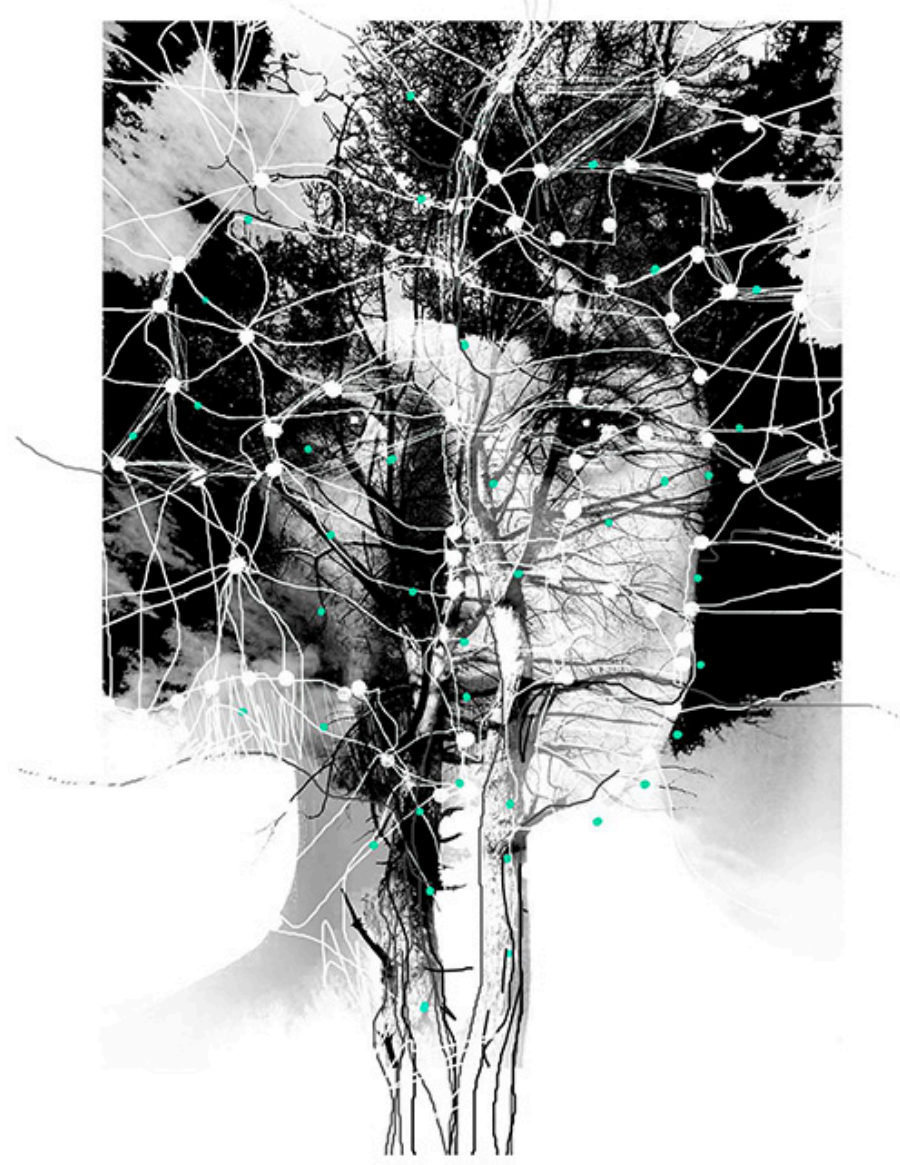

SOY EL BOSQUE. VG* 


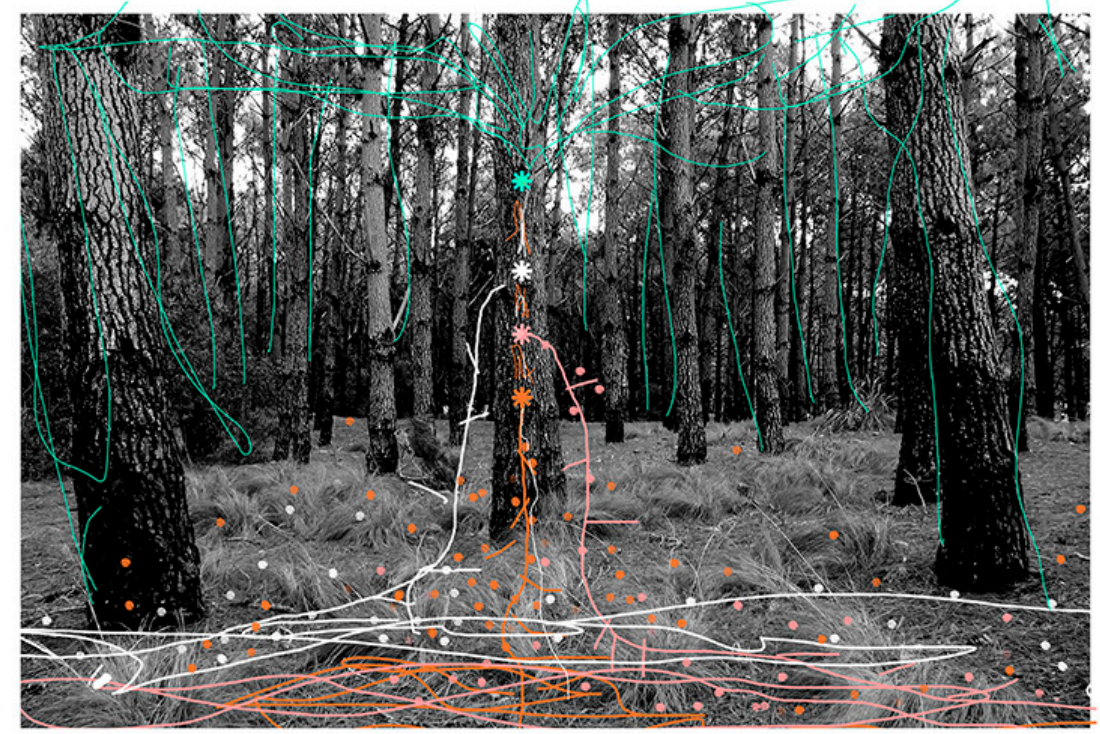

SOY EL BOSQUE / VG.

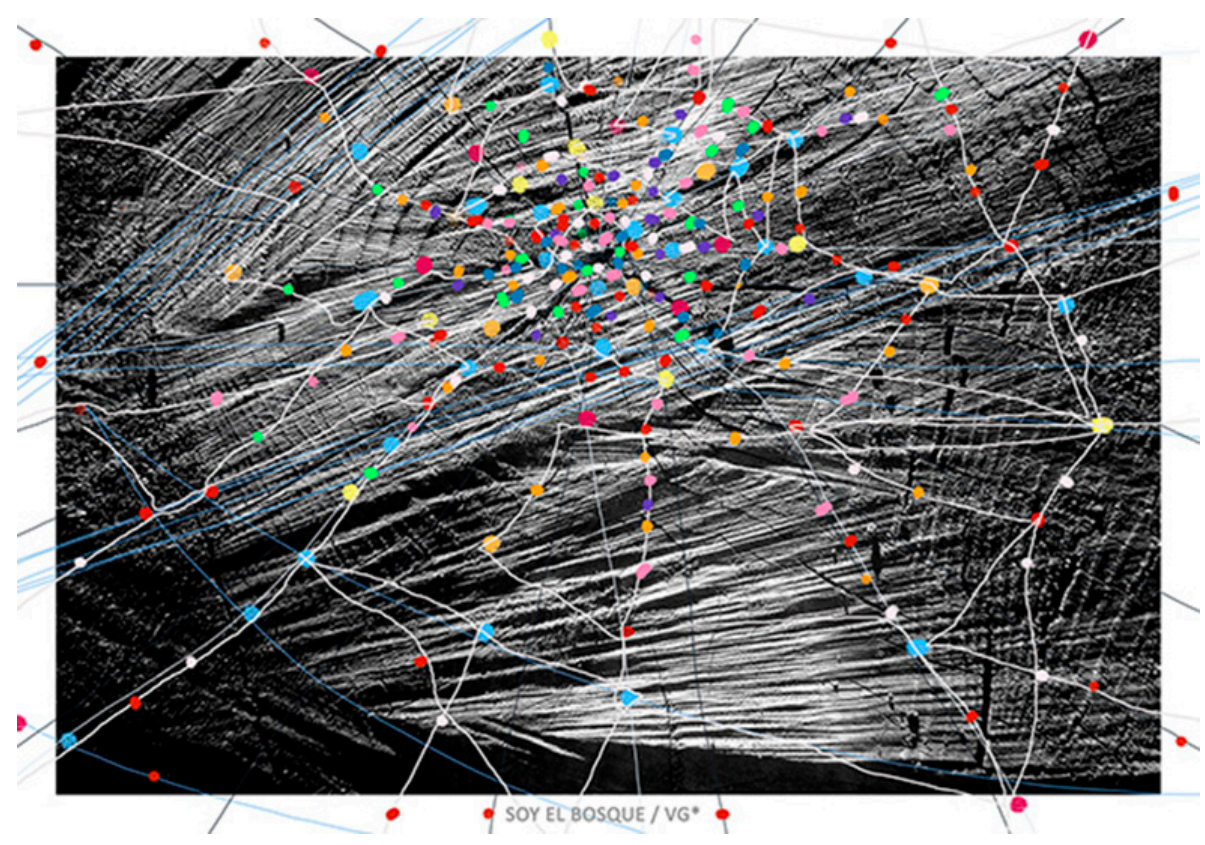




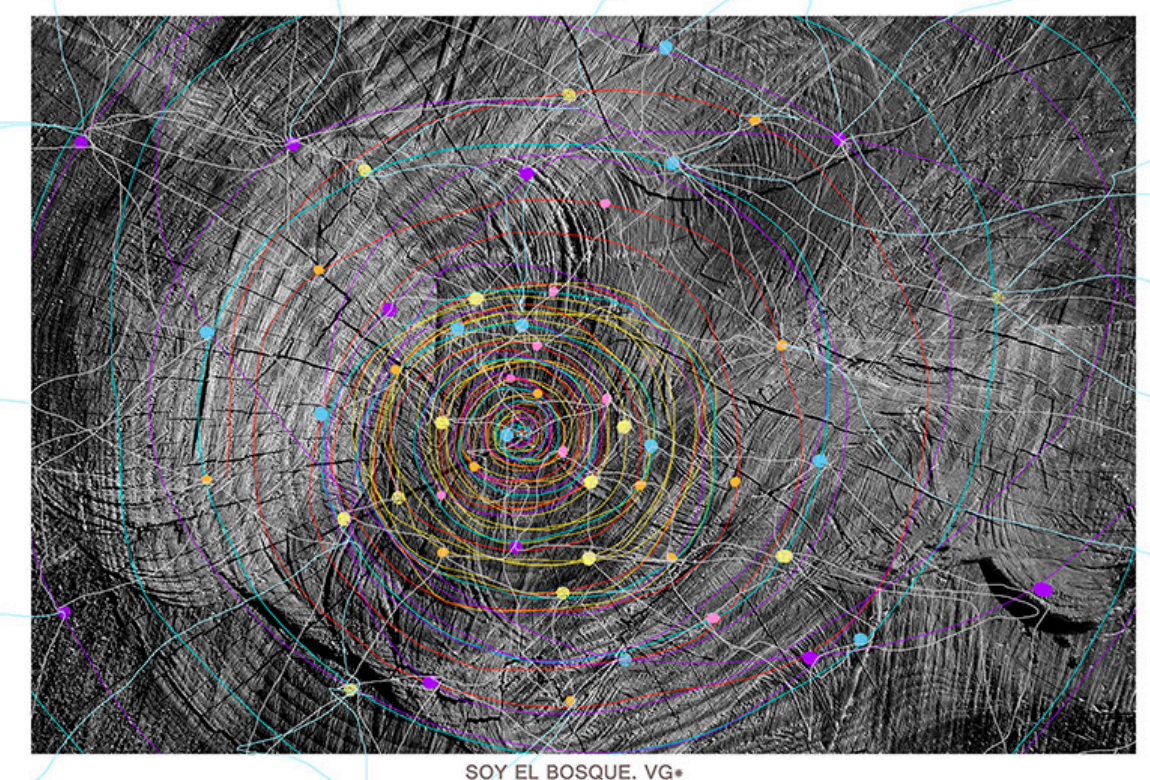

SOY EL BOSQUE. VG. 


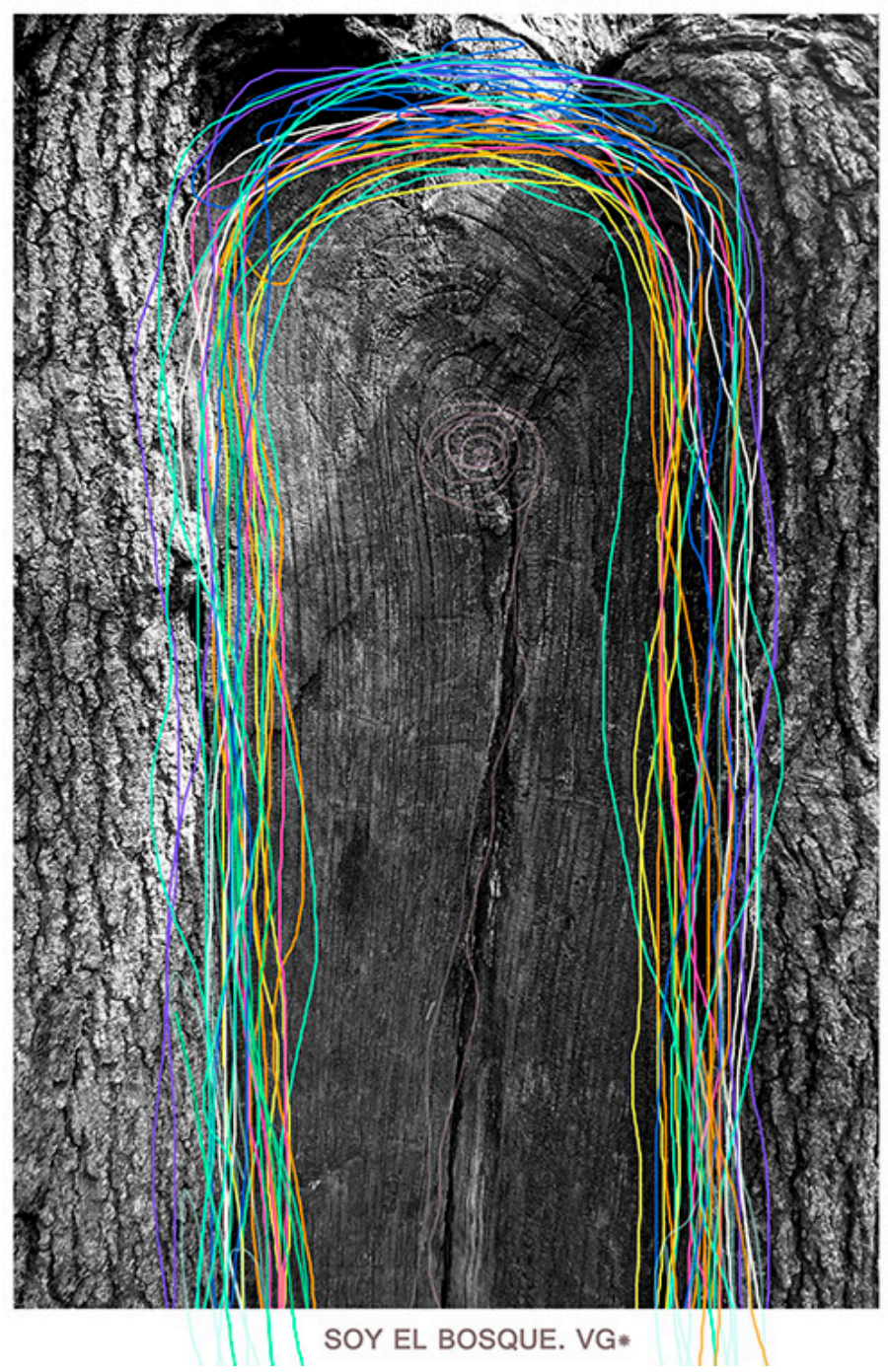




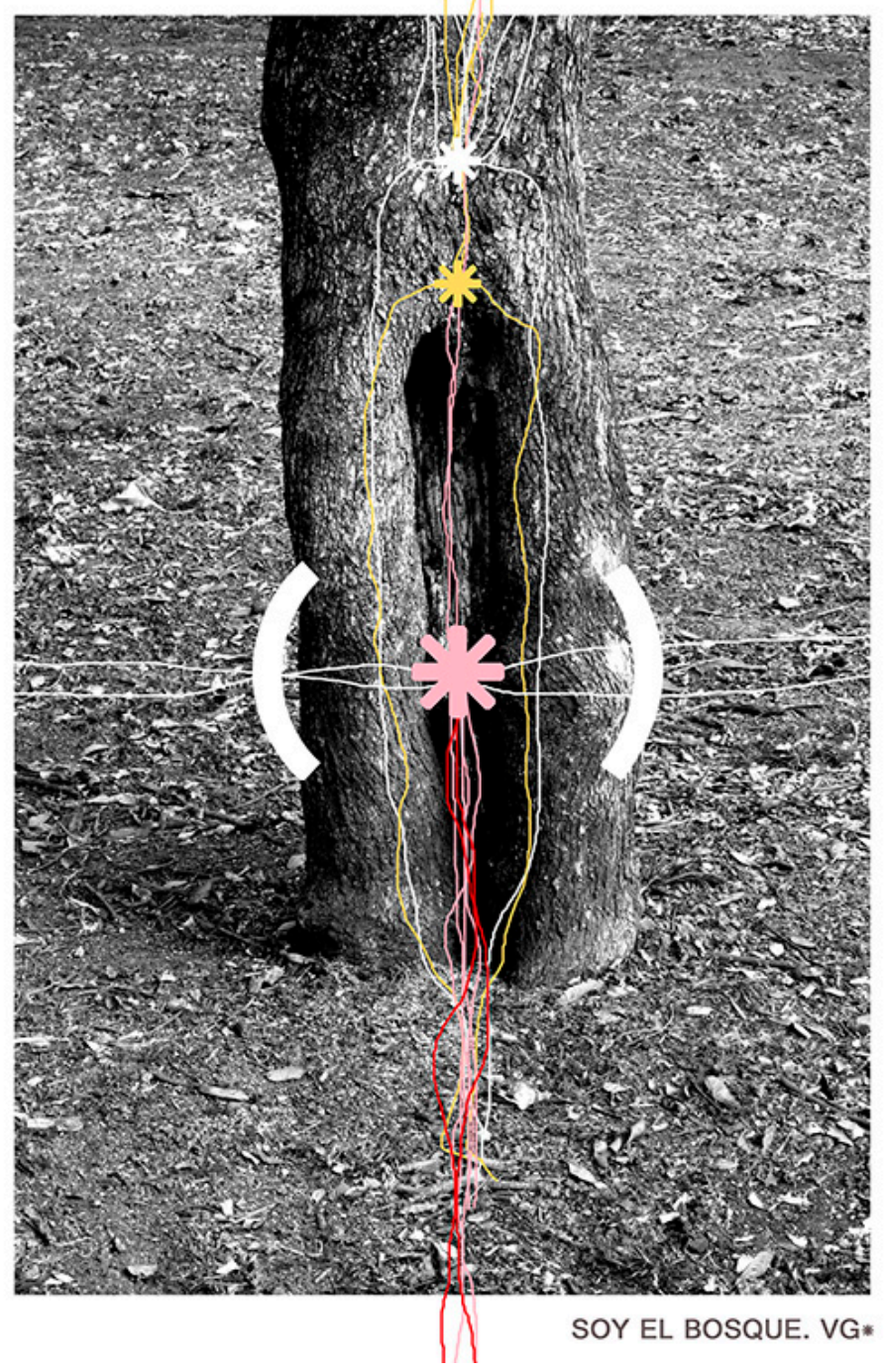




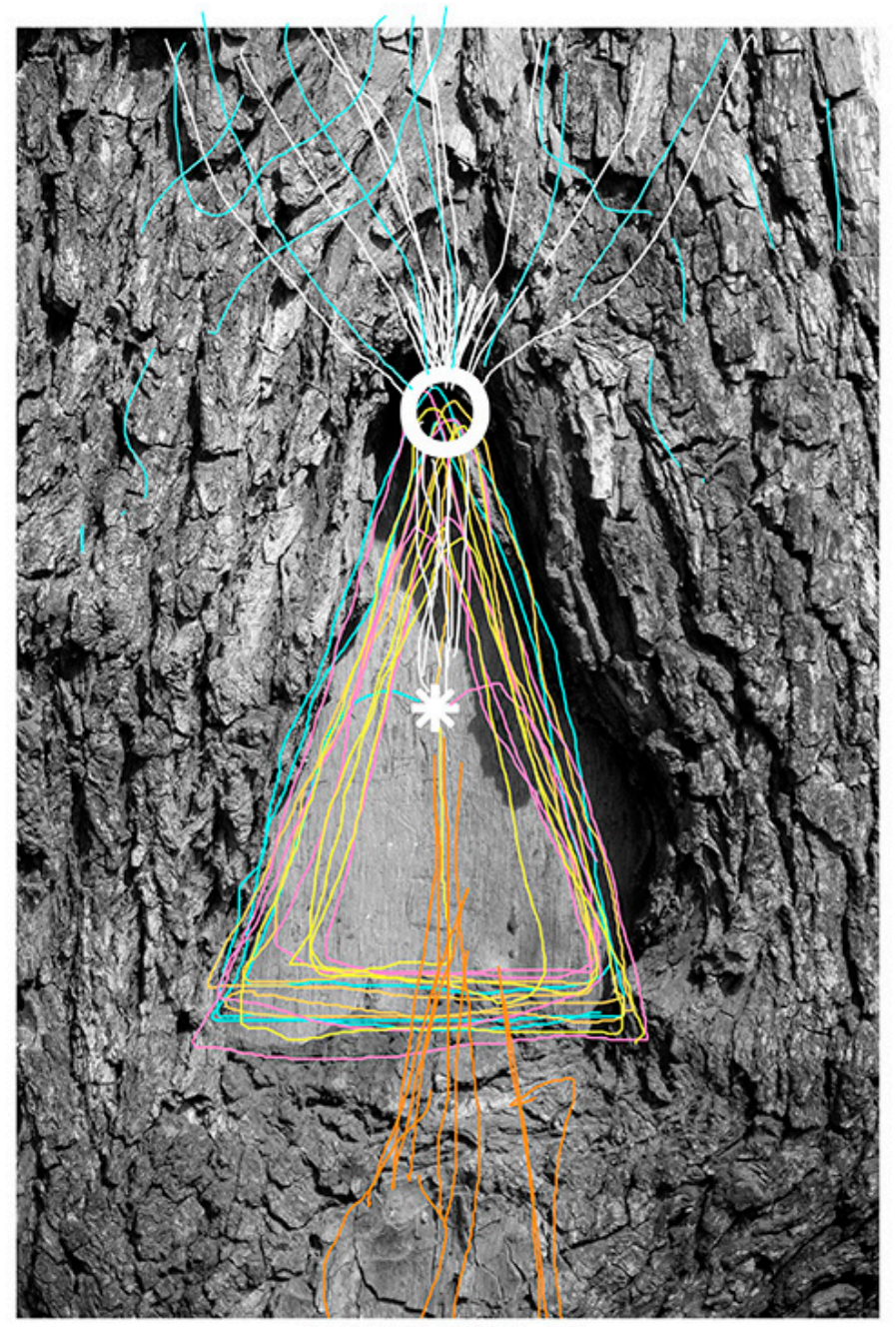

SOY EL BOSQUE. VG* 


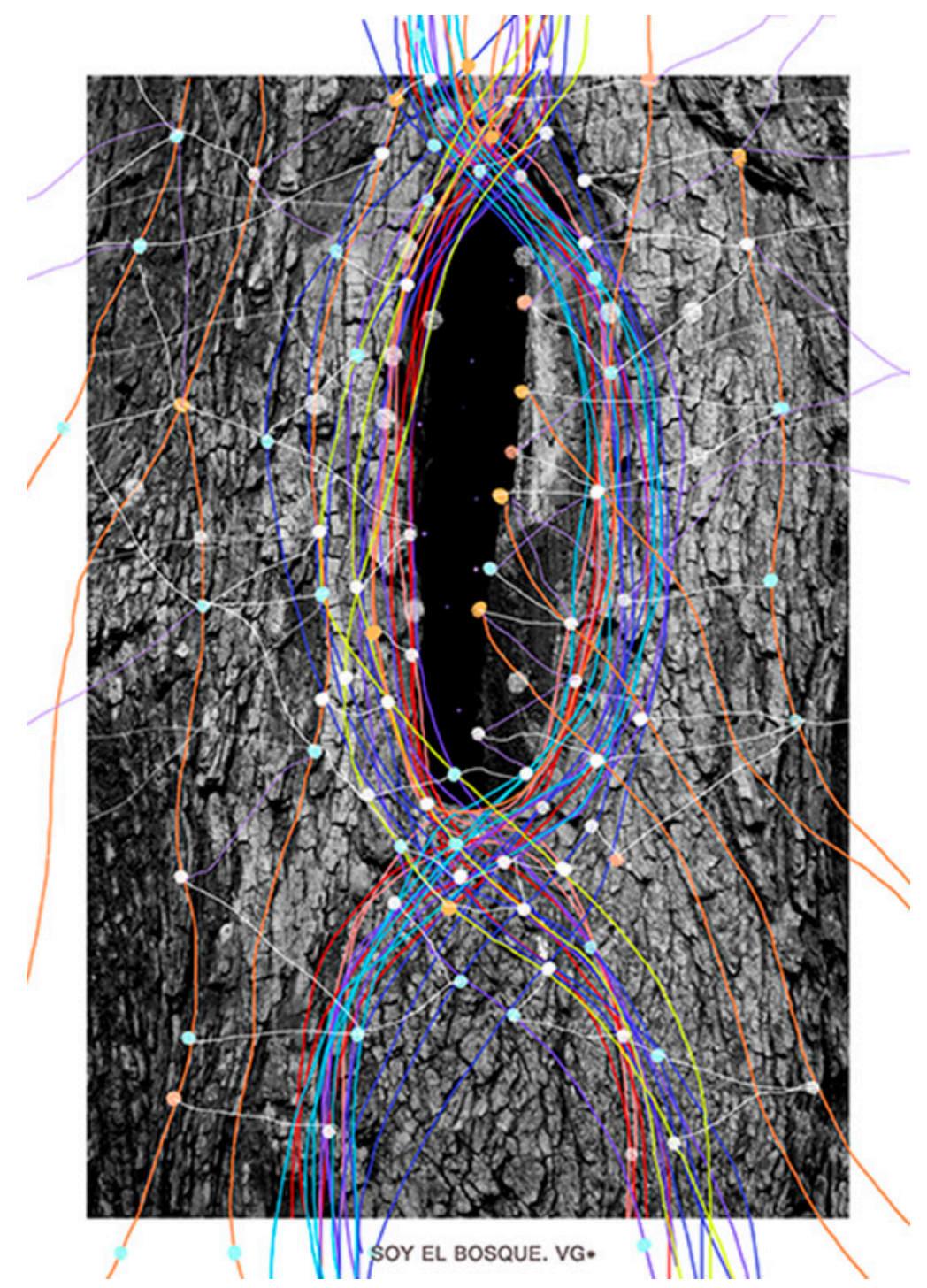

\section{Adentro}

se acerca húmeda

$$
\text { la tierra }
$$

empapada

despacio

en el viento

me salpica

los ojos los labios los ojos

el bosque es una mujer con lengua de corteza 
secas vivas

verdes muertas

flores

no la miro

no voy a quedarme

con las manos ella envuelve

mojada

regalos con piel de musgo varita mágica de nena buena

con los ojos me pide corazones de pólvora de naftalina de azafrán me quiebra encantada

estoy en el borde

suenan pájaros picos árboles nubes con voces de abrojo

se ensancha ella me respira me sopla

entonces

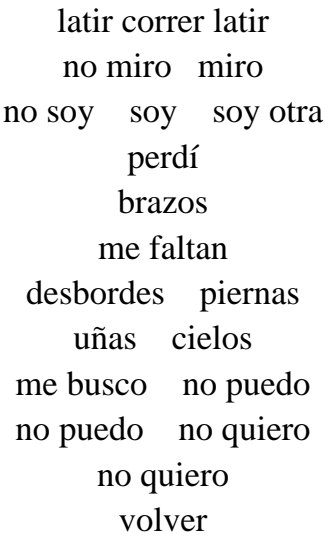

el tiempo hacia atrás 